\title{
A pilot study of quality of life, mood, sleepiness and fatigue in patients with primary humoral immunodeficiency transitioning to subcutaneous immunoglobulin therapy
}

\author{
Persia Pourshahnazari ${ }^{*}$, Gina Tsai ${ }^{2}$, Adriana Martin $^{3}$, Amin Kanani $^{3}$, Donald Stark ${ }^{3}$, R Robert Schellenberg ${ }^{3}$ \\ From Canadian Society of Allergy and Clinical Immunology Annual Scientific Meeting 2014 \\ Ottawa, ON, Canada. 23-26 October 2014
}

\section{Background}

Immunoglobulin replacement therapy is standard of care for patients with primary humoral immunodeficiency [1]. Compared with intravenous immunoglobulin (IVIG), subcutaneous immunoglobulin (SCIG) offers comparable efficacy, lower costs and reduced systemic reactions [2,3]. However, little is known about effects on quality of life when patients transition from IVIG to SCIG. It was our objective to assess changes in quality of life, mood, sleepiness and fatigue in patients transitioning from IVIG to SCIG.

\section{Methods}

Adult patients with common variable immunodeficiency or X-linked agammaglobulinemia transitioning from IVIG to SCIG were invited to participate in this prospective, open-label, pilot study. At least one set of Short-Form 36 Health Survey (SF-36), Profile of Mood States (POMS), Epworth Sleepiness Scale (ESS) and nighttime sleep questionnaires was administered prior to the final IVIG infusion. These were repeated monthly for 3 months following the transition. Magnitude of change was estimated between IVIG trough and final SCIG steady-state data. Statistical significance was determined using linear mixed models for repeated measures with Kenward-Rogers correction.

\section{Results}

Twenty-seven patients were included in the analysis. Two of eight SF-36 quality of life domains showed significant

'Department of Internal Medicine, University of British Columbia, Vancouver, British Columbia, Canada

Full list of author information is available at the end of the article improvement: role limitations due to physical health $(\mathrm{p}=$ $0.01)$ and emotional problems $(\mathrm{p}=0.04)$. Two of six POMS mood subscales significantly improved: depression $(\mathrm{p}=0.03)$ and anger $(\mathrm{p}=0.04)$. One of six POMS mood subscales (tension, $\mathrm{p}=0.08$ ) and POMS total mood disturbance scores $(\mathrm{p}=0.09)$ trended towards improvement. No significant changes were noted in ESS or nighttime sleepiness scores.

\section{Conclusions}

Patients transitioning from IVIG to SCIG for treatment of primary antibody immunodeficiency showed significant improvement in several quality of life and mood subscales. A larger study verifying these findings could encourage patients to switch to SCIG self-administration, producing quality of life benefits while decreasing health care costs.

\begin{abstract}
Authors' details
${ }^{1}$ Department of Internal Medicine, University of British Columbia, Vancouver, British Columbia, Canada. ${ }^{2}$ Department of Medicine, Division of Allergy \& Immunology, Schulich School of Medicine \& Dentistry, Western University, London, Ontario, Canada. ${ }^{3}$ Department of Medicine, Division of Allergy and Clinical Immunology, University of British Columbia, Vancouver, British Columbia, Canada.
\end{abstract}

Published: 18 December 2014

\section{References}

1. Chapel HM: Consensus panel for the diagnosis and management of primary antibody deficiencies: consensus on diagnosis and management of primary antibody deficiencies. Br Med J 1994, 308:581-585.

2. Abolhassani H, Sadaghiani MS, Aghamohammadi A, Ochs HD, Rezaei N: Home-based subcutaneous immunoglobulin versus hospital-based intravenous immunoglobulin in treatment of primary antibody deficiencies: systematic review and meta analysis. J Clin Immunol 2012, 32(6):1180-92. 
3. Ho C, Membe S, Cimon K, Roifman C, Kanani A, Morrison A: Subcutaneous versus intravenous immunoglobulin for primary immunodeficiencies: systematic review and economic evaluation. Technology report number 98 Ottawa: Canadian Agency for Drugs and Technologies in Health; 2008.

doi:10.1186/1710-1492-10-S2-A37

Cite this article as: Pourshahnazari et al: A pilot study of quality of life, mood, sleepiness and fatigue in patients with primary humoral immunodeficiency transitioning to subcutaneous immunoglobulin therapy. Allergy, Asthma and Clinical Immunology 2014 10(Suppl 2):A37.

Submit your next manuscript to BioMed Central and take full advantage of:

- Convenient online submission

- Thorough peer review

- No space constraints or color figure charges

- Immediate publication on acceptance

- Inclusion in PubMed, CAS, Scopus and Google Scholar

- Research which is freely available for redistribution

Submit your manuscript at www.biomedcentral.com/submit
C Biomed Central 